\title{
From the Center
}

\section{Tools for the Hospitality Industry}

E arlier this year, the Center for Hospitality Research (CHR), the publisher of the Cornell Quarterly, launched a new type of content on its Web site. Posted under the rubric Tools for the Hospitality Industry, this new content will offer you a variety of helpful ways to improve your operation. We launched these Tools to provide yet another service to the industry, beyond the written content found in this journal and our CHR Reports series.

In this essay, I will tell you a little about three of the tools, namely, the Turnover Cost Evaluator, Mega Tips, and the Restaurant Table Mix Optimizer. My hope is that you will get a good idea of the nature of the tools from these descriptions.

\section{Turnover Cost Evaluator (TCE)}

The TCE was developed from the research, teaching, and consulting of Professors Tim Hinkin and Bruce Tracey of the School of Hotel Administration at Cornell University. TCE, a Web application, is an excellent tool for understanding the direct and indirect costs associated with turnover. It can help you calculate how much you are spending to replace line, mana- gerial, and executive staff. The rationale for using TCE is that if you better understand the costs of turnover, then you can develop more effective strategies to reverse the negative effects of this endemic problem. The TCE's structure allows you to evaluate the cost of turnover for anything from a single job position to an entire organization. This tool also allows you easily to model different turnover scenarios.

\section{Mega Tips (MT), or Scientifically Tested Techniques to Increase Your Tips}

$M T$ was developed by Professor Mike Lynn, also of the School of Hotel Administration at Cornell University. Professor Lynn has studied and written extensively about tipping behavior, including several articles in this journal. $M T$ is a booklet for servers that provides instruction in the psychology of tipping and gives specific techniques that servers can use to earn larger tips. All the suggested techniques have been scientifically tested, and the evidence of their effectiveness is described along with the techniques. Using even a few of these techniques should increase servers' tips by 10 to 30 percent. Managers who want to boost 
both sales and tips are free to download the $M T$ booklet, print and copy it, and either post it on employee bulletin boards or distribute copies directly to their servers. Managers who distribute the $M T$ booklet to their servers should benefit from increased sales, greater customer satisfaction, and lower labor costs due to reduced server turnover.

\section{Restaurant Table Mix Optimizer (RTMO)}

I designed the RTMO to help managers find the best mix of tables for their restaurants, in terms of revenue and service standards. As inputs, the RTMO requires information that most managers already have available: the percentage of total parties that fall in each size (e.g., parties of one constitute 20 percent of total parties), the average dining duration by party size, the average check by party size, the number of seats to be placed in the restaurant, and which table sizes can be used. As outputs, the RTMO identifies the maximum number of parties that can be served per hour, the maximum average revenue per available seat-hour (RevPASH), and which table combinations are best used to serve each size party. RTMO is a Webbased tool that allows you to create, evaluate, and save different scenarios. This enables you to determine the effect on performance of such things as changing which table sizes you have in your dining room.

\section{Tools to Come}

The CHR plans to release a number of additional tools, including tools for evaluating training interventions, optimizing labor staffing plans for businesses with pronounced seasonal patterns in customer demand, checklists for disaster planning, and estimating the value of a room reservation. To use any of the tools, start by following the link for "Tools for the Hospitality Industry" that you will find on the CHR Web site (TheCenterForHospitality Research.org). Our hope is that collectively, these tools will help your businesses operate more effectively.-G.M.T. 